\title{
Professional competence build-up among future teachers and teaching psychologists during professional training
}

\author{
F.P. Khakunova ${ }^{1 *}$, Z.Z. Shkhakhutova ${ }^{2}$, and $A . K$. Bersirova ${ }^{3}$ \\ ${ }^{1}$ Adyghe State University, Maykop, Russia \\ ${ }^{2}$ Adyghe State University, Maykop, Russia \\ ${ }^{3}$ Adyghe State University, Maykop, Russia
}

\begin{abstract}
This article deals with the specifics of practical professional training among future teachers and teaching psychologists. The said specialists receive professional training during practical studies. Recently the focus of attention shifted to justifying the contents of professional training which is conducive to the build-up of professional competences. Thusly, we deemed it rational to expose a number of issues and problems student cope with during work experience. We defined markers of professional competence build-up and presented the follow-up diagnostics results of the said practice.
\end{abstract}

\section{A problem statement}

Recent and considerable changes within the higher pedagogical education system predetermine new tasks for professional training of qualified graduates with pedagogics and psycho-pedagogics majors.

At this stage labor market requires specialists with professional experience, astute, highly adaptable and mobile within their work environment, responsive to the demands of existing pedagogical reality.

Recently issued directives (National Educational Doctrine till 2025, Modernization Concepts of Russian education - till 2020., Federal State Standards of Higher Education (FSES HE), Professional Teaching Standard) steer professional pedagogical education towards training well-educated and highly qualified specialists set on professional growth and agility within social digitalization and high-end technology developments [1].

This new type of specialist requires searching for suitable content defining concepts which help students to systemize cognitive processes of laws and principles of psychopedagogical activity as well as corresponding organizational matters [2].

Educational standards $3++$ emphasize the following points for pedagogical and psychopedagogical education: the importance of practical training; well-defined professional activities and competences required for performing specialized work.

\footnotetext{
*Corresponding author: ipcs-profped@yandex.ru
} 
Current educational doctrine anticipates a brand new approach to organizing practical studies [3]. Teaching practice is crucial for professional competence build-up because it instigates students' proficiency in both theory and practice of pedagogical processes at any given age: early, pre-school, primary school, teenage, adolescent and early adulthood [4]. This explains variety of practices [5].

A graduate of psycho-pedagogical major should have a wholly formed professional competence which is understood as readiness for solving professional tasks.

This readiness manifests itself professionally. Moreover, it develops and shapes itself through professional activities. Thus, in order to increase professional competence levels, students are to be introduced to activities conducive to their professional growth and improvement from their first study year.

\subsection{The objective of the work}

Psycho-pedagogical theory analysis revealed that besides a number of fundamental studies dedicated to organizational issues of students' practical training (Abdullina, Belozertsev, Gorlenko, Grebenyuk, Necheporenko, Piskunov, Slastenin, Slobodchkov, et al.) there are recent dissertational research works dealing with the practical issues of professional teacher training [6].

Various organizational issues of said practice, its relevance for recent graduates' skill set are addressed in works by Bakulina, Burlak, Belousova, Gudzenko, Koroleva, Rubtsova, et al [7].

Implementation issues of the outcome-based approach in the context of teacher professional training and activity of teachers and teaching psychologists are reflected in research studies by Baryshnikova [Baryshnikova, 2015], Biserova [Biserova, 2015], Giniyatova [Giniyatova, 2016], Ivanov [Ivanov, 2015], Sitarov [Sitarov, 2004], Tukhvatullina [Tukhvatullina, 2015], Feshchenko [Feshchenko, 2011] and others [8].

Professional training issues of prospective teachers and teaching psychologists within the existing altercations interest a number of scientists. Among them - Bakhmetova [Bakhmetova, 2013], Lazareva [Lazareva, 2013], Lebedeva [Lebedeva, 2016], Novikova [Novikova 2008], Razdul'eva [Razdul'eva, 2008], Seitbattalova [Seitbattalova, 2009], Shevyreva [Shevyreva, 2013], Shkerina [Shkerina, 2011] et al [9].

According to Dmitrienko, Meshcheryakova and Obraztsov, students' acquisition of necessary professional and personal skill set, conducive to their professional occupation can only be effective if practical training and techniques are implemented in their studies [10].

However, the overall majority of professional training and organization research is dedicated to the development of cognitive and pragmatic personality traits of students. While training ought to focus not only on the acquisition of the required skillset and work experience but on the acquiring emotionally expressive reactions as well [11].

The following issues remain unaddressed: contents of practical studies according to every function, as well as its growing complexity, starting with general introduction to various types of educational establishments, examination and analysis of incoming data to completion of increasingly complex tasks.

\section{Materials and the results of the research}

Addressing the issue of professional competence build-up among future teachers and teaching psychologists during practical studies from a theoretical perspective disclosed the following inconsistencies:

- between the necessity of FSES HE 3++ implementation, regulating diverse types of practices within the educational process of a given educational establishment and the 
absence of content plans and programs for every type of training with reference to the required competence skillset acquired during practical studies;

- between the outcome-based approach doctrine stipulating the contents and organization of psycho-pedagogical training as one of the crucial components of professional training and the lack of techniques and methodological basis for organizing the said practice as well as implementing the outcome-based approach in the process.

Conflict resolution contributed to defining the research problem, based on detecting the informative component of the training program and the organization thereof with reference to professional competence build-up.

Thus, we set the following tasks:

- detecting terms, forms and methods of practical training of future teachers and teaching psychologists;

- defining the potential of pedagogical practice in building up professional competence among future teachers and teaching psychologists;

- working out the contents of various practices in accordance with required educational competences;

- defining students' professional competence levels during training.

Pedagogics Department at Adyghe State University was our research facility for studying professional competence build-up among future teachers and teaching psychologists. Our experimental subjects were ASU students with «Psychological and pedagogical education» major, 138 students in total.

According to FSES HE training is implemented via outcome-based approach. Practical training is a crucial component of the basic higher educational program, a compulsory part of study drills and the learning process in genera [12]. It is implemented in order to extend and reinforce theoretical knowledge as well as acquire practical skills. We formulated the following basic functions and tasks of pedagogical practice:

- reinforce, extend and deepen students' knowledge of theory as well as improve their practical skills and competences;

- harness basic methods, techniques and means of teaching in diverse educational establishments in order to apply them when working with children, teachers and parents;

- conduct psychological follow-ups of pre-school and school pupils as well as co-work with reference to learning, treatment and development issues in families and various types of educational establishments;

- facilitate acquisition of research experience and professional standpoint in future teachers and teaching psychologists as students;

- learn to select required psychodiagnostic techniques and tests for further examination as well as analyze obtained results;

- promote professionally significant qualities in future teaching psychologists;

- promote creative activity and positive motivation towards their future profession [13].

Professional training also fulfills the following functions: adaptive (a future teacher, or teaching psychologist not only acquaints oneself with diverse types of psycho-pedagogical activities but immerses oneself in interacting with all participants of pedagogical process: children, homeroom teacher, other teachers, parents and adapts oneself to the rhythm of the school's educational process), educational (a future teaching psychologist tests the amount of acquired theoretical knowledge in the professional field, reinforcing and extending it), educative (it manifests itself in forming professional motivation, self-worth and individual teaching style of future teachers or teaching psychologists), developmental (deals with forming and improving their skill as well as creative potential), diagnostic (aimed at detecting personality traits and professional qualities of future teachers or teaching psychologists). 
Each type of practice implies acquisition of certain competences. Thus, student practice (1-2 Year) should result in forming of the following professional competences:

- ability to implement acquisition and development programs dealing with universal educational actions, aimed at achieving metadisciplinary educational results among pupils;

- ability to harness and apply professionally basic theoretical and scientific knowledge together with practical skills [14];

- ability to reconstruct educational content according to FSES subject specifications for basic and secondary education as well as levels of scientific progress and age requirements of the pupils [15];

- ability to organize joint and individual educational and educative activities for the pupils including those with special educational requirements with reference to FSES specifications [16].

Contents of students' training include assignments aimed at: implementing the pedagogical education and evolution techniques for the pupils including those with special educational requirements; acquisition of certain practical skills and competences in planning, project and research work at any given educational facility; students' professional competence training aimed at fulfilling pedagogical functions with merit, as due to the subject of professional activity; forming of personal, emotive, value-conscious attitude in pupils towards project and research activities of their teacher; harnessing and practical application of a number of technologies (personality-based technologies in learning; interactive technologies (instructional design, problem-based learning, gamification, teamwork, case technology, intensive technologies for thought-provoking); ICT (content implementation), forms and methods of research and project work; mastering the basics of research and project work by all participants of the educational process via educational outreach activity, socio-cultural work and leisure; development and application of effective psych-pedagogical, inclusive tools in practice, thereby improving individual learning, selfgrowth and educative requirements of the pupils, including those with special educational requirements [17].

Work experience internship (Years 2-4) implies mastering the following competences:

- ability to carry out your professional routine with reference to policy framework, rules and regulations pertaining to pedagogical activities and work ethics;

- students' ability to organize joint and individual educational and educative activities for their pupils, including those with special educational requirements with reference to FSES specifications [18];

- ability to apply in practice psycho-pedagogical techniques, thereby improving individual learning, self-growth and educative requirements of the pupils, including those with special educational requirements;

- ability to interact with all participants of educational relationships in the process of implementing educational programs;

- ability to implement acquisition and development programs dealing with universal educational actions, aimed at achieving metadisciplinary educational results among pupils;

- ability to harness and apply professionally basic theoretical and scientific knowledge together with practical skills;

- ability to reconstruct educational content according to FSES subject specifications for basic and secondary education as well as levels of scientific progress and age requirements of the pupils.

Contents of students' training include assignments aimed at: students' acquisition of skills and abilities for independent educative work with their pupils with reference to their individual differences and maintaining health care; acquisition of certain practical skills and competences; improving their educational planning and analyzing skills; refining their lesson planning and teaching skills; fulfilling their responsibilities as teachers, teaching 
psychologists via applying a variety of techniques aimed at activating cognitive activities in their pupils; rational use of scientifically valid practices, methods and means, including new educational and ICT technologies; mastering individual approach techniques with reference to age requirements and specifications of the pupils; introspection, self-evaluation, selfreflection and readjustment skills; self-preparation for fulfilling your responsibilities as a teacher, or teaching psychologist; refining contact establishing techniques with the parents, their involvement in the educational process; analysis of a teacher, or teaching psychologist' actions in implementing FSES rules and regulations and pertaining documentation; reflective analysis of essential professional and personal skills and capabilities [19].

The build-up of professional competence among future teachers and teaching psychologists was evaluated with reference to the following markers:

- work-related sustainable interest manifestations;

- interpersonal interaction (with pupils, their parents, other teachers);

- performance analysis of both pupils and teachers, psychological assessment skills;

- activity planning, materials, methods and techniques selection skills;

- organizational skills (team work, group work, individual work);

- ties and contacts establishing skills (with pupils, other teacher, colleagues, parents);

- use of contemporary teaching techniques, including ICT;

- ability to create a co-working, amicable environment;

- self - and reflective analysis of psycho-pedagogical activity.

The summative research stage focused on examining the original level of professional competence build-up in our subjects. Reporting documents analysis (training journals, lesson notes, training sessions, test results, individual work with pupils and their parents, occupational guidance with high school students, training self-reflection reports, questionnaires, discussions, students' monitoring activities) show that the main problems the majority of students deals with during training are: self-awareness issues as a prospective teacher or teaching psychologist - 58\%; difficulties with reference to interpersonal interaction (with pupils, their parents, other teachers) (there are some issues with organizational matters or with the pupils' individual differences) $-34 \%$; performance analysis of both pupils and teachers, psychological assessment skills - 43\%; activity planning, materials, methods and techniques selection skills $-37 \%$; organizational skills (team work, group work, individual work) $-33 \%$; ties and contacts establishing skills (with pupils, other teacher, colleagues, parents) $-49 \%$; use of contemporary teaching techniques, including ICT $-23 \%$; ability to create a co-working, amicable environment - $26 \%$; selfand reflective analysis of psycho-pedagogical activity $-31 \%$.

During the summative research stage of our experiment we implemented training organization program, the contents of which focused on the professional competences build-up among prospective teachers [20]. After the completion of the said stage according to the outcome-based approach we received the following results. Both the reporting documents analysis and our own observations show that the applied training program not only enriched and improved our subjects' skillset and knowledge but contributed to their personal growth, as they noted in their reports. The majority of students lost their fears of conducting and preparing interactive lessons. Thus, we can conclude that professional competence contributed to their sense of self-confidence, increased their demands and requirements for their professional skillset. The conducted post-training students' questionnaire revealed the following results: self-awareness issues as a prospective teacher or teaching psychologist remained in $12 \%$; initial interaction issues (with pupils, their parents, other teachers) decreased to $9 \%$; issues with performance analysis of both pupils and teachers, psychological assessment skills decreased to $16 \%$; harnessed activity planning, materials, methods and techniques selection skills - $67 \%$ of students; 
organizational skills (team work, group work, individual work) improved in - 79\%; ties and contacts establishing skills (with pupils, other teacher, colleagues, parents) mastered by $74 \%$; use of contemporary teaching techniques, including ICT $-71 \%$; Self- and reflective analysis of psycho-pedagogical activity implemented by $-69 \%$ of students.

The post-training test results on identifying the level of professional competence buildup are shown in table 1.

Table 1. Results of professional competence build-up indicators.

\begin{tabular}{|l|l|l|}
\hline Professional competence build-up markers & $\begin{array}{l}\text { Summative } \\
\text { stage } \\
\text { research }\end{array}$ & $\begin{array}{l}\text { Formative } \\
\text { stage } \\
\text { research }\end{array}$ \\
\hline $\begin{array}{l}\text { Work-related sustainable interest manifestations, self- } \\
\text { awareness as a teacher, teaching psychologist }\end{array}$ & $58 \%$ & $88 \%$ \\
\hline $\begin{array}{l}\text { Interpersonal interaction (with pupils, their parents, other } \\
\text { teachers) }\end{array}$ & $34 \%$ & $91 \%$ \\
\hline $\begin{array}{l}\text { Performance analysis of both pupils and teachers, } \\
\text { psychological assessment }\end{array}$ & $43 \%$ & $84 \%$ \\
\hline $\begin{array}{l}\text { Activity planning, materials, methods and techniques } \\
\text { selection skills }\end{array}$ & $37 \%$ & $67 \%$ \\
\hline $\begin{array}{l}\text { Organizational skills (team work, group work, individual } \\
\text { work) }\end{array}$ & $33 \%$ & $79 \%$ \\
\hline $\begin{array}{l}\text { Ties and contacts establishing skills (with pupils, other } \\
\text { teacher, colleagues, parents) }\end{array}$ & $49 \%$ & $74 \%$ \\
\hline Use of contemporary teaching techniques, including ICT & $23 \%$ & $71 \%$ \\
\hline $\begin{array}{l}\text { Self- and reflective analysis of psycho-pedagogical } \\
\text { activity }\end{array}$ & $31 \%$ & $69 \%$ \\
\hline
\end{tabular}

\section{Conclusions}

The contents and organization of training programs, as well as the systematic work of the students themselves in recognizing the necessity of their chosen field and harnessing the ways of its implementation influence the success of professional competence build-up in teachers and teaching psychologists.

Students; setting of professional goals during training is of crucial importance. Primary personality traits that provide positive motivation are: interest in the subject, content, process and results of the educational activity; character of mutual relations with all participants of the educational and educative process which manifests itself in emotive and evaluative actions; ability to self-regulate educational activities, relationships and states as an indicator of students; self-identity.

Thus, every type of training practice provides reinforcement and practical application of theory, harnessing the required professional skillset and acquisition of professional work experience as well as notions and practical ideas of teaching as a professional occupation, improvement of professional skills and abilities and acquisition of competences that constitute the basis of professional competence of future teachers and teaching psychologists.

During our research we worked out and implemented both functions and tasks of the training which contributed to students' active incorporation into interpersonal interaction with the participants of the educational process; build-up of professional motivation of future educators, development of self-reflection and self-evaluation skills, psychological assessment and follow-up assessment skills.

Research results show that during training future educators have exhibited significant increase in the build-up of the following professional competences: work-related 
sustainable interest manifestations; lateral and systems thinking; ability to act independently under conditions of uncertainty; ability to take on professional responsibilities; readiness for positive interaction and cooperation; readiness for constant professional advancement; sustainable commitment to self-improvement, self-education and self-fulfillment; healthy lifestyle; information competences; cross-cultural competences; soft skills (Shevchenko, 2017) [21].

We note that the conducted research and acquired results can be viewed as basis for further inquisition on the subject. We consider as viable research on the issues of detecting organizational terms of professional training with reference to ongoing innovative and informational processes within our education system; issues of educational and methodological follow-up activities during all types of professional training at various education; defining criteria, diagnostic and evaluation methods and indicators of professional competences build-up level among future teachers and teaching psychologists during professional training.

\section{References}

1. N. Popova, O. Eremina, Professional standard "Teacher": from theory to practice, Pedagogical education in Russia, 3, 15-21 (2017)

2. D.A. Danilov, Conceptual approach to personalizing students training for professional pedagogical activity. Siberian pedagogical journal, 6, 29-35 (2006)

3. S.L. Ivashevskiy, Present day character of ideologizating education, Vlast', 2, 91-96 (2010)

4. N.G. Arzamastseva, L.V. Kurochkina, Educational practice as a condition for the formation of professional competencies of students, Bulletin of the Mari State University, 14, 11-17 (2020)

5. A.A. Glebov, V.V. Kislyakov, Problem-based approach to the formation of students ' ability to apply knowledge in practice, Proceedings of the Volgograd State Pedagogical University, 3, 31-34 (2016)

6. D.I. Feldstein, The relationship between theory and practice in the formation of psychological and pedagogical foundations of modern education, Problems of modern education, 6, 10-20 (2010)

7. N.Yu. Kifik, Role of pedagogical training in professional emergence of future teaching psychologists, Pedagogical science and practice, 1, 55-60 (2013)

8. O.V. Katurzhevskaya, Implementation of the competence approach in the professional training of future teachers, Azimuth of scientific research: pedagogy and psychology, 5, 64-67 (2016)

9. E.V. Baryshnikova, Psycho-pedagogical conditions of professional competence buildup in future teaching psychologists, Vestnik of South Ural State Humanitarian Pedagogical University, 8, 18-24 (2015)

10. L.V. Lviv, The role of skills in achieving professional competence of future specialists, Education and science, 5, 94-107 (2004)

11. V.Yu. Vanieva, Theoretical and applied aspects of implementing a practical training system for educators, Azimuth of scientific research: pedagogics and psychology, 5, 24-26 (2016)

12. M.V. Ugryumova, Placement and designation of disciplines and practices in the curriculum of educational programs of higher education, Concept, 11, 7-20 (2017) 
13. E.M. Tretyakova, College students' professional competences build-up during pedagogical practice, Azimuth of scientific research: pedagogics and psychology, 4, 98-102 (2015)

14. E.K. Henner, Professional knowledge and professional competencies in higher education, Education and science, 20 (2), 9-31 (2018)

15. E.G. Drunk, About the design features of approximate basic educational programs for the federal state educational standard 3++. Scientific and pedagogical review, Pedagogical Review, 3, 9-19 (2019)

16. O.S. Kuzmina, N.V. Chekaleva, Ways and methods of forming in students work aptitudes when working with pupils with special requirements, Vestnik of Omsk State Pedagogical University, Humanitarian research, 3, 151-154 (2019)

17. I.V. Kuzina, E.V. Lyovkina, V.F. Mironycheva, N.V. Fedoseeva, Pedagogical practice project and organization techniques for extramural students with pedagogical education majors, Humane sciences, 1, 100-108 (2018)

18. F.P. Khakunova, The problem of the content of practice-oriented training of future teachers' collection of scientific papers of the IY, International forum on teacher education and the ISSAT regional conference, 2, 322 (2018)

19. L.N. Lipatova, Students' independent work: aim, objectives, principles and forms, World of science and education, 2 (2015)

20. O.I. Vaganova, Formation of technological competence of the future teacher of professional training in the course of practice, Concept, 11, 2-3 (2019)

21. E.V. Shevchenko, On the issue of improving the professional competencies of students of a pedagogical University in the process of training and practical training, Concept, 11, 88-93 (2017) 